\title{
Fundamentalismo, Bíblia e Relações de Gênero
}

\author{
Alexandre de Jesus dos Prazeres*
}

\section{RESUMO}

Neste artigo, foi realizada uma dupla interpretação do fundamentalismo: sociológica e teológica. Primeiro, foi empreendida uma interpretação sociológica na qual o fundamentalismo foi analisado enquanto uma reação ao pluralismo moderno e sua consequente relativização das tradições pré-modernas. Estas tradições deixam de ser aceitas conforme dadas e passam a ser percebidas como uma possibilidade em meio a outras. Segundo, foi realizada uma interpretação teológica do fundamentalismo. Para este fim, recorreu-se a contribuições oriundas da reflexão teológica de Paul Tillich. E terceiro, buscou-se aplicar os resultados desta dupla interpretação à hermenêutica bíblica, especificamente ao tema das relações de gênero na Bíblia.

Palavras-chave: fundamentalismo; modernidade; Paul Tillich; hermenêutica; relações de gênero.

\section{FUNDAMENTALISM, BIBLE, AND GENDER RELATIONS}

\begin{abstract}
A sociological and theological interpretation of fundamentalism is presented in this paper. First, a sociological interpretation, which fundamentalism is assumed as a reaction to modern pluralism and its consequent relativization of pre-modern traditions. These traditions are no longer mainly accepted, for they are perceived as one possibility among other possibilities. Second, a theological interpretation of fundamentalism appealing Paul Tillich's theological reflection is placed in question. Finally, the paper deals with a double interpretation to biblical hermeneutics as
\end{abstract}

* Doutor em Sociologia pela Universidade Federal de Sergipe; mestre em Ciências da Religião e Bacharel em Teologia pela Universidade Católica de Pernambuco. Professor no Programa de Pós-Graduação em Ciências da Religião da Universidade Federal de Sergipe. https://orcid.org/0000-0001-5241-7690. 
results of this dialogue, specifically to the theme of gender relations in the Bible.

Keywords: Fundamentalism; Modernity; Paul Tillich; Hermeneutics; Gender relations.

\section{Introdução}

O fundamentalismo possui uma dinâmica própria, surge com este nome no contexto do Cristianismo protestante estadunidense, todavia esta mesma dinâmica pode ser identificada em outras religiões e até mesmo no contexto de manifestações seculares. Antes que sejam descritos os elementos que identificam o fundamentalismo é necessário reconhecer que se trata de algo latente em todas as culturas, sejam elas explicitamente religiosas ou não, mas que se torna consciente quando as certezas e a segurança a respeito delas são de alguma forma abaladas. É a dúvida que se estabelece quando o que outrora em uma cultura era aceito como dado passa a ser percebido como relativo, uma possibilidade entre diversas outras. $\mathrm{O}$ apego veemente as tradições e a tudo o que possa reestabelecer a segurança das certezas é um modo para ocultar a crise instaurada pela dúvida. E, no contexto do Ocidente cristão, é a Modernidade o fator que desperta as consciências individuais ou coletivas para a relatividade inerente a quaisquer culturas, forçando o ser humano moderno a conviver com dúvidas.

Mais adiante se abordará o modo como o fundamentalismo em contexto moderno se tornou uma das principais formas de se lidar com a dúvida. Mas antes disto é preciso entender algumas mudanças ocasionadas nas culturas modernas, forçando as pessoas destas culturas a lidar com a relatividade presente no modo como compreendem a realidade a partir de suas culturas. Neste primeiro momento, empreende-se uma interpretação sociológica do fundamentalismo, principalmente com o auxílio de elementos conceituais da Sociologia do Conhecimento. Este primeiro momento contribuirá, descrevendo o contexto social mais amplo da Modernidade, e auxiliará a interpretação teológica do fundamentalismo apresentada no segundo momento neste texto. Nesta tarefa, conceitos presentes na reflexão teológica de Paul Tillich foram empregados, objetivando trazer clareza à discussão. E, por fim, considerando estas exposições, no terceiro momento, discutir-se-á questões relacionadas à hermenêutica bíblica e às relações de gênero. 


\section{Modernidade e Pluralismo}

No campo sociológico, é Peter Berger uns dos primeiros a despertar para a necessidade de se compreender melhor este fenômeno de certezas abaladas pelas transformações produzidas pelo advento da Modernidade. Berger, inicialmente, direciona este seu despertamento para conclusão de que a Modernidade é secularizante. Assim, ele torna a secularização um problema para a pesquisa sociológica e elabora uma teoria clássica a respeito do tema. A perspectiva de Berger sobre a secularização, nesta fase inicial de suas pesquisas, pode ser encontrada em seus textos da década de sessenta.

No Dossel sagrado, um destes textos da década de sessenta, Berger (1985) já sinaliza como preocupação até que ponto a tradição religiosa do Ocidente teria trazido em si mesma as sementes da secularização, claro que operando em conjunto com outros fatores. Ao fazer isto, Berger está considerando a noção de que o protestantismo desempenhou um papel particular no estabelecimento do mundo moderno com base em Weber, principalmente em A ética protestante e o espírito do capitalismo, e Ernst Troeltsch e suas pesquisas sobre protestantismo e Modernidade. Destes autores foi possível chegar ao entendimento de como o protestantismo aboliu a maior parte das mediações que sustentavam o mundo católico medieval. Uma vez que se compreenda que a vida neste mundo católico consistia em viver imerso em situações nas quais o sagrado é mediado por uma série de canais (os sacramentos da Igreja, a intercessão dos santos, a erupção recorrente do sobrenatural em milagres). Berger (1985, p.125) concluiu que o protestantismo:

[...] rompeu a continuidade, cortou o cordão umbilical entre o céu e a terra, e assim atirou o homem de volta a si mesmo de uma maneira sem precedentes na história. Não é preciso dizer que não era essa a sua intenção. Seu objetivo, ao despir o mundo, era acentuar a terrível majestade do Deus transcendente e, ao atirar o homem num estado de "queda" total, abri-lo à intervenção da graça soberana de Deus, o único verdadeiro milagre no universo protestante. Fazendo isto, porém, o protestantismo reduziu o relacionamento do homem com o sagrado ao canal, excessivamente estreito, que ele chamou de palavra de Deus (o que não se deve identificar com uma concepção fundamentalista da Bíblia, mas com a excepcional ação redentora da graça de Deus - a sola gratia das confissões luteranas). 
Berger sustenta que o protestantismo funcionou como um prelúdio historicamente decisivo para a secularização, sem deixar de reconhecer a importância de outros fatores. Todavia, amparado em Weber e seus escritos sobre o Judaísmo antigo, está consciente de que o potencial secularizante do protestantismo tem suas raízes em elementos anteriores na tradição bíblica. Em outros termos, o "desencantamento do mundo" começa no Antigo Testamento, principalmente por este postular um Deus que está fora do cosmo, radicalmente transcendente, algo que tirou do cosmo o seu status de divino e eterno como estava proposto pelo paganismo greco-romano.

No Dossel sagrado e nos demais textos deste período, tais como Rumor de anjos e $O$ imperativo herético, Berger explora elementos para uma teoria sociológica da religião, porém sob o escopo de sua área de interesse sociológico, a Sociologia do Conhecimento. Sendo esta uma área que possui o seu processo de sistematização iniciado a partir da década de vinte. Sistematização iniciada por pesquisadores alemães como Max Scheler e Karl Mannheim. Este último define esta então nascente área de pesquisa sociológica nos seguintes termos:

[...] a sociologia do conhecimento procura compreender o pensamento dentro de uma moldura concreta de uma situação histórico-social, de que o pensamento individualmente diferenciado emerge mui gradualmente. Assim, não são os homens em geral que pensam, nem mesmo os indivíduos isolados, mas os homens dentro de certos grupos que elaboraram um estilo peculiar de pensamento graças a uma série interminável de reações a certas situações típicas, características de sua posição comum (MANNHEIM, 1952, p.3).

A Sociologia do Conhecimento se preocupa com a relação entre o pensamento humano e as condições sociais sob as quais o pensamento emerge. Neste horizonte, Berger propõe, em textos desta fase, que se considere o conceito de "estruturas de plausibilidade" para se lidar com a forma como a sociedade pensa e explica os fenômenos com os quais se depara.

Uma das proposições fundamentais da sociologia do conhecimento é que a plausibilidade, no sentido daquilo que as pessoas realmente acham digno de fé, das ideias sobre a realidade depende do suporte social que estas 
ideias recebem. Dito mais simplesmente, nós conseguimos nossas noções sobre o mundo originalmente de outros seres humanos, e estas noções continuam sendo plausíveis, para nós em grandíssima parte, porque os outros continuam a afirmá-las. [...] Claro que é possível ir contra o consenso social que nos cerca, mas há pressões fortes (que se manifestam como pressões psicológicas dentro de nossa própria consciência) para nos conformarmos às visões e crenças de nossos semelhantes (BERGER, 2018, p.64).

Desta fase inicial das pesquisas de Berger sobre a secularização, pode-se detectar que este compreende que no contexto moderno as pessoas passaram a coexistir numa pluralidade de mundos, migrando de um lado a outro entre estruturas de plausibilidade rivais e muitas vezes contraditórias, uma provocando um enfraquecimento da outra simplesmente pelo fato de sua coexistência involuntária com outras estruturas de plausibilidade. Esta pluralização é a causa da decrescente plausibilidade das tradições religiosas. O que uma vez foi aceito como "natural", inevitável, ou autoevidente passa agora a ser visto como uma possibilidade dentre tantas outras e produto de um contexto histórico-social específico. Nesta fase, Berger compreende a Modernidade como secularizante e que a secularização, indo além de suas manifestações socioestruturais, instaurou-se na consciência dos sujeitos modernos, uma "consciência secularizada" que se contrapõe à "consciência religiosa".

Todavia, em textos mais recentes, Berger abandona a sua teoria acerca da secularização. Segundo ele, isto ocorreu devido ao entendimento de que os dados empíricos contradiziam a teoria. Posto de outra forma, a teoria sociológica clássica tem como ideia básica que a Modernidade acarreta necessariamente um declínio da religião, porém os dados empíricos com os quais Berger (2017, p.11) teve contato o conduzem a percepção de que, com algumas exceções, particularmente na Europa e uma determinada intelectualidade internacional, o nosso mundo não é nada secular, ele é tão religioso como outrora, e em alguns lugares mais ainda.

Apesar disto a Modernidade ocasionou o surgimento de um fenômeno novo, e diante desta constatação, $\operatorname{Berger}(2017$, p.9) realiza a seguinte proposição: 
Proponho que um novo paradigma deveria ser capaz de lidar com dois pluralismos - a coexistência de diferentes religiões e a coexistência de discursos religiosos e seculares. Esta coexistência ocorre não somente nas mentes dos indivíduos, mas também no espaço social.

No bojo desta proposição, está o entendimento de que a secularidade ocidental não é a única forma de modernidade, havendo outras versões da modernidade nas quais se concede à religião um lugar muito mais central. Esta compreensão se orienta pelo conceito elaborado por Samuel Eisenstadt a respeito de "modernidades múltiplas".

Mesmo assim, Berger (2017, p.12) está ciente, enquanto especialista em Sociologia do Conhecimento, que uma percepção básica desta área é que "caso queira funcionar na sociedade, toda instituição deve ter um correlato na consciência". Ou seja, "se ocorreu uma diferenciação entre as instituições religiosas e as outras instituições na sociedade, esta diferenciação deve também ter-se manifestado na consciência dos indivíduos".

Conforme já mencionado acima, a questão básica para os que continuam advogando a teoria clássica da secularização é que a Modernidade, a qual esta se associa, acarreta necessariamente um declínio da religião. Mas uma vez abandonada esta questão básica, alguns sociólogos passaram a advogar um retorno do sagrado ou dessecularização. Por sua vez, Berger buscou se situar numa posição intermediária, a Modernidade não é necessariamente secularizante e produtora de declínio da religião, mas produz uma existência em convívio com a pluralidade que obriga religiosos a realizar o equilíbrio entre as suas crenças religiosas e a realidade global do discurso secular. Isto foi apresentado pelo próprio Berger (2017, p.15) nos termos seguintes:

Contudo, agora estou preparado para conceder que os teóricos da secularização não estão tão errados como eu achava antes. Compreendo agora mais plenamente a realidade global do discurso secular, não só na Europa e nas associações do corpo docente em todo o mundo, mas também na vida de muitos crentes comuns que conseguem ser tanto seculares quanto religiosos. Eu diria que são estas pessoas que realizam o ato de equilíbrio cognitivo prototípico da modernidade, e com este ato modificam a forte dicotomia entre os teóricos da secularização e aqueles que anunciam "o retorno dos deuses". 
Na Modernidade, o pluralismo (ou diferentes maneiras de apreender a realidade) se tornou um fato empírico na sociedade amplamente experimentado pelas pessoas. A Modernidade é o produto de mudanças provocadas pela ciência e tecnologia nos últimos séculos. Este processo se tornou cada vez mais acelerado e suas consequências afetaram um número cada vez maior de áreas da vida humana. Já no início deste processo a humanidade passou a vivenciar uma expansão da urbanização sem precedentes históricos. Pessoas oriundas de ambientes rurais que viviam sob os ditames de uma economia feudal passaram conviver em centros urbanos atraídas pela Revolução Industrial e a nova economia capitalista. Meios de transporte cada vez mais velozes possibilitaram viagens para todas as partes do mundo, aproximando pessoas das mais diferentes culturas e de lugares longínquos. E recentemente as novas tecnologias da informação produziram uma revolução digital e tecnológica, possibilitando uma imensa rede de relacionamentos entre pessoas de todas as partes do planeta, bem como um enorme acesso a informações sobre as mais variadas tradições e costumes humanos. Assim, o pluralismo se torna globalizado.

O pluralismo, porém, relativiza e com isto enfraquece muitas das certezas com as quais os seres humanos costumavam conviver. Isto conduz ao próximo ponto, a relação entre fundamentalismo, Modernidade e as incertezas geradas pela relativização consequente da existência em meio ao pluralismo globalizado.

\section{Modernidade e Fundamentalismo}

Até aqui foi apresentado o arcabouço teórico para uma interpretação sociológica do fundamentalismo, principalmente quando se considera que o ser humano moderno foi exposto a uma experiência de pluralismo. E "o pluralismo provoca uma situação na qual a relativização se torna uma experiência permanente” (BERGER, 2017, p.24). Esta é uma das razões para as inquietações, não somente de religiosos institucionalmente comprometidos, mas de pessoas modernas em geral sejam elas declaradamente religiosas ou não. A calma produzida pelas certezas das sociedades pré-modernas se foi, mas permanece muito atraente para quem busque um porto seguro para escapar ou se esconder das dúvidas. 
Em meio a esta conjuntura, Berger (2017, p.33-34) explica que "há duas tentativas aparentemente opostas, mas de fato profundamente semelhantes, para aliviar a inquietação trazida pela relativização: o fundamentalismo e o relativismo".

O fundamentalismo é um esforço para restaurar a certeza ameaçada. O termo é geralmente aplicado a movimentos religiosos, mas é importante compreender que há muitos fundamentalismos seculares - políticos, filosóficos, estéticos e mesmo culinários (como no caso de alguns vegetarianos) ou atléticos (como na fidelidade a um determinado time esportivo). Praticamente qualquer ideia ou prática pode se tornar o fundamento de um projeto fundamentalista, em níveis muito diferentes de sofisticação - como, por exemplo, nas semelhanças e diferenças entre um teórico marxista e um fanático crente na redução de peso. Além disso, o projeto pode consistir em voltar a uma certeza (real ou imaginária) do passado (p. ex., o catolicismo tradicional) ou em olhar com uma postura de segurança para o futuro (como no caso da maioria dos movimentos revolucionários modernos). Em outras palavras, há fundamentalismos reacionários e progressistas. $\mathrm{O}$ que todos esses projetos têm em comum é uma promessa para o convertido potencial: "Junte-se a nós, e você terá a certeza que você há muito deseja. Você compreenderá o mundo, saberá quem você é e saberá como viver" (BERGER, 2017, p.34).

Há "fundamentalismos reacionários e progressistas". Os fundamentalismos reacionários entram em conflito com as mudanças do presente, reagindo contra estas mudanças por meio da afirmação de tradições do passado como fundamentos. Por sua vez, os fundamentalismos progressistas também reagem a alguma situação presente. Não às mudanças, mas a tudo o que for identificado como mau no presente, segundo um juízo de valor próprio. O modo como esta reação se manifesta é através da afirmação como fundamento de algo de cunho ideológico, uma nova ordem social ideal ou a noção de mundo melhor. Neste caso, o fundamento é utópico por existir apenas enquanto uma aposta ideológica em uma possibilidade do que o mundo possa vir a ser. Este tipo de fundamentalismo motiva as ações de propostas políticas revolucionárias. Berger (2017, p.35) prossegue em seu argumento, expondo que o fundamentalismo carrega consigo uma promessa de certeza. E esta promessa provavelmente será cumprida para os que estiverem dispostos a aceitar os pressupostos cognitivos e normativos do projeto fundamen- 
talista. E quem for capaz de continuar aceitando estes pressupostos ao longo do tempo viverá com um novo sentido de convicção. Porém este sentido carrega uma vulnerabilidade, principalmente quando comparado à convicção da humanidade pré-moderna. Pois para os seres humanos pré-modernos, a cosmovisão e o sistema de valores são dados como certos e aceitos sem que qualquer reflexão ou decisão seja necessária. Por sua vez, a experiência prometida pelo fundamentalismo não é igual a vivenciada na pré-modernidade, em sociedades nas quais a tradição não é escolhida, mas aceita conforme dada exatamente por ser a única forma de conceber a realidade que as pessoas enraizadas na tradição conhecem. O que o fundamentalismo promete é de outra ordem. É um neotradicionalismo assumido como forma de se contrapor às incertezas trazidas pela relativização moderna. Os neotradicionalistas não conseguem ser tolerantes com os que não compartilham a sua tradição. Pois para eles, a tradição não é simplesmente dada, eles a escolheram e não podem esquecer isto. Ou seja, eles podem até afirmar sonoramente a tradição como uma pessoa pré-moderna fazia antigamente, mas sempre haverá um tom velado de incerteza que contribui para uma situação muito diferente. "Os fundamentalistas", conclui Berger, "são agressivos na mesma medida em que são vulneráveis".

Em outros termos, a busca por certeza agora se materializou na escolha por abraçar uma tradição, porém a escolha será sempre ameaçada pela possibilidade de outras escolhas que um ambiente plural proporciona. Uma vez que a tradição escolhida já não é mais compreendida como algo dado ou certo, mas como uma dentre muitas outras formas de compreender o mundo.

Porém um lembrete importante é feito por Berger (2017, p.40) acerca das duas tentativas de aliviar as inquietações produzidas pela relativização moderna: o fundamentalismo e o relativismo. Que é um grande erro achar que a maioria das pessoas na sociedade moderna é constituída ou de fundamentalistas ou de relativistas. Quando de fato a maioria das pessoas não estão preocupadas com teorizações. As pessoas podem até serem fundamentalistas ou relativistas, mas na maior parte do tempo estão inconscientes disto, só refletindo a respeito quando surge um problema que afeta suas vidas. As teorizações, na maior parte do tempo, são deixadas para os especialistas. Berger explica que "a 
maioria das pessoas vive no meio-termo entre negar e louvar a relatividade. Elas conseguem viver na situação pluralista administrando-a pragmaticamente".

Consciente desta perspectiva sociológica sobre o fundamentalismo, acrescenta-se a esta também agora uma perspectiva teológica para descrever o modo como o fundamentalismo funciona nas consciências dos sujeitos que aderem a sua proposta. Já está claro que o fundamentalismo é uma reação desesperada à Modernidade. Esta reação pode ser percebida, no que se refere ao Cristianismo, tanto no Catolicismo quanto no Protestantismo. No seio do Protestantismo, esta reação surgiu com o nome de fundamentalismo, por sua vez, no Catolicismo surgiu como integralismo. A diferença básica é que no fundamentalismo protestante a Bíblia é confundida com Deus ou Palavra de Deus, e um conjunto de doutrinas "fundamentais" são compreendidas como expressões da mente e sentimentos divinos; já no integralismo católico é a Igreja que é confundida com Deus, suas tradições e ensinamentos como expressões da mente e sentimentos divinos. No fim das contas, católicos, protestantes ou qualquer outra pessoa que assuma posturas fundamentalistas ou integralistas estão unidos na mesma confusão que consiste em absolutizar o que é historicamente condicionado, e exatamente por isto relativo.

Para uma compreensão teológica deste fenômeno, recorre-se aqui à reflexão empreendida pelo teólogo alemão Paul Tillich. Já na primeira página da introdução à sua Teologia sistemática, Tillich (2002) fornece dados sobre a sua interpretação do fundamentalismo. Ele está discorrendo sobre as necessidades básicas que a teologia deve satisfazer: "a afirmação da verdade da mensagem cristã e a interpretação desta verdade para cada nova geração". São dois polos entre os quais os sistemas teológicos precisam se equilibrar: "a verdade eterna de seu fundamento e a situação temporal na qual a verdade eterna deve ser recebida". Para Tillich, o problema específico do fundamentalismo consiste em que devido ao temor de perder a verdade eterna, os fundamentalistas a identificam com conceitos e soluções tradicionais relacionados com algum sistema teológico anterior. No Protestantismo, isto tem sido evidenciado através do biblicismo evangelical no qual "a verdade teológica de ontem é defendida como mensagem imutável contra a verdade teológica de hoje e amanhã". Deste modo, o fundamentalismo fracassa na tentativa 
de entrar em contato com a situação presente. Isto, segundo Tillich, não porque fale desde além de qualquer situação, mas porque ele fala desde uma situação do passado. Neste ponto da discussão, Tillich faz uma afirmação que é primordial para o entendimento de como teologicamente o fundamentalismo se relaciona com a realidade. Tillich $(2002$, p.13) afirma que o fundamentalismo:

Eleva algo finito e transitório a uma validez infinita e eterna. Neste sentido o fundamentalismo tem traços demoníacos. Ele destrói a humilde honestidade da busca pela verdade, divide a consciência de seus seguidores que refletem, e os torna fanáticos. Isto porque são forçados a suprimir elementos da verdade dos quais eles estão veladamente conscientes.

"O fundamentalismo tem traços demoníacos" porque "eleva algo finito e transitório a uma validez infinita e eterna", esta afirmação é melhor entendida à luz dos critérios para o empreendimento teológico e da concepção de divindade propostos por Tillich. Para Tillich (2002, p.180), "tudo aquilo que preocupa o homem de forma última se torna deus para ele", desta forma, Tillich (2002, p.20) entende que "o objeto da teologia é aquilo que nos preocupa de forma última. Só são teológicas aquelas proposições que tratam de seu objeto na medida em que ele pode se tornar questão de preocupação última para nós”. Perceba-se que ele entende que o objeto da teologia não é nem um conceito específico de deus (como o conceito cristão) e nem se primeiro existe um ser chamado Deus, e então a exigência de que o ser humano esteja ultimamente preocupado com Ele, mas o que preocupa o ser humano de forma última, conforme já explicitado, torna-se deus para ele.

Por sua vez, além da preocupação última há também as preocupações preliminares. De acordo com Tillich (2002, p.21) há três relações possíveis das preocupações preliminares com aquilo que preocupa os humanos de forma última: a primeira é de indiferença mútua; a segunda é a relação na qual uma preocupação preliminar é elevada à ultimacidade; e a terceira é aquela em que uma preocupação preliminar se torna veículo de preocupação última, sem reivindicar ultimacidade para si mesma. A segunda relação é a que contribui para o entendimento da razão de Tillich ter afirmado que "o fundamentalismo tem traços demoníacos”, pois para Tillich (2002, p.21): 
A segunda relação é idolátrica por própria natureza. Idolatria é a elevação de uma preocupação preliminar à ultimacidade. Algo essencialmente condicionado é considerado incondicional. Algo essencialmente parcial é elevado à universalidade. E algo essencialmente finito é revestido de significado infinito.

O fundamentalismo quando eleva algo preliminar (seja uma tradição, ou um sistema teológico, ou até mesmo um texto sagrado como a Bíblia) à ultimacidade se torna idolátrico por elevar algo essencialmente condicionado à incondicionalidade, algo parcial à universalidade. Para Tillich (2002, p.22), "nada pode ser de preocupação última para nós se não tiver o poder de ameaçar e salvar nosso ser", e, por sua vez, "'ser' significa a totalidade da realidade humana, a estrutura, o sentido, e o alvo da existência”.

Neste ponto específico, está claro que algo pode se tornar demoníaco devido a sua condição idolátrica de algo preliminar elevado à ultimaticidade. Mas além deste ponto, há outro que pode esclarecer ainda mais a natureza do que é demoníaco. Tillich (2002) discorre sobre o sentido da "revelação" (esta compreendida, dentre outras coisas, enquanto manifestação daquilo que nos diz respeito de forma última) e como um evento subjetivo e objetivo que mantém uma interdependência estrita. Objetivamente a revelação se dá por meio do que tradicionalmente foi chamado de "milagre", e subjetivamente em termos do que foi às vezes chamado de "êxtase". Tillich (2002, p.99-100) esclarece com qual concepção de "êxtase" está lidando nas seguintes palavras:

"Êxtase ("estar fora de si mesmo") aponta para um estado da mente que é extraordinário no sentido de que a mente transcende sua situação ordinária. Êxtase não é uma negação da razão; é o estado da mente no qual a razão está além de si mesma, isto é, além da estrutura sujeito-objeto. Ao estar além de si mesma, a razão não nega a si mesma. "Razão extática" permanece razão; ela não recebe nada irracional ou anti-racional - o que não poderia fazer sem autodestruição - mas ela transcende a condição básica da racionalidade finita, a estrutura sujeito-objeto. Este é o estado que os místicos tentam alcançar por atividades ascéticas e místicas. Mas os místicos sabem que essas atividades só são preparações e que a experiência do êxtase é devida exclusivamente à manifestação do mistério em uma situação revelatória. O êxtase ocorre só se a mente é possuída pelo mistério, isto é, pelo fundamento do ser e sentido. E, vice-versa, 
não há revelação sem êxtase. No máximo há uma informação que pode ser testada cientificamente.

Compreendido o significado de êxtase, observe-se, no pensamento tillichiano, como este é contraposto ao que é demoníaco:

O estado extático no qual ocorre a revelação não destrói a estrutura racional da mente. Os relatos sobre experiências extáticas na literatura clássica das grandes religiões coincidem neste ponto - que, enquanto que a possessão demoníaca destrói a estrutura racional da mente, o êxtase divino a preserva e eleva, embora a transcenda. Possessão demoníaca destrói os princípios éticos e lógicos da razão: o êxtase divino os afirma. "Revelações" divinas são expostas e rejeitadas em muitas fontes religiosas, especialmente no Antigo Testamento. Uma pretensa revelação, na qual a justiça como princípio da razão prática é violada, é antidivina. Portanto, é considerada uma mentira. O demoníaco cega; não revela. No estado de possessão demoníaca a mente não está de fato "fora de si mesma". Ela de fato está em poder de elementos dela mesma, que aspiram ser a totalidade da mente, que se apoderam do centro do eu racional e o destroem (TILLICH, 2002, p.101).

Agora é possível concluir que o que é demoníaco além de ser idolátrico, o transitório elevado à ultimacidade, também é destruidor. Destrói "a humilde busca pela verdade, divide a consciência" e conduz ao fanatismo. "O demoníaco cega; não revela". Demoníacos são elementos da própria mente "que aspiram à totalidade da mente, que se apoderam do centro do eu racional e o destroem". E, neste sentido, o fundamentalismo é demoníaco por se constituir em um estado mental de cegueira, idolatria, confusão mental provocada por elementos na própria mente que se apoderaram da sua racionalidade e provocaram a sua destruição, fazendo com que a mente se torne fanática, forçada a suprimir elementos da verdade dos quais está veladamente consciente.

Há ainda mais uma possibilidade de reflexão teológica sobre o fundamentalismo com o auxílio da produção intelectual de Paul Tillich que não deve ser deixada de fora desta discussão. A referência é ao que foi pensado por Tillich (1976) sobre "ser", "não-ser" e "ansiedade", no livro A coragem de ser. "Pois se o ser é interpretado em termos de vida, ou processo, ou vir a ser, o não-ser é ontologicamente tão fundamental quanto o ser”, explica Tillich (1976, p.25-26). Este compreende que o 
"ser" tem o "não-ser" dentro de si mesmo, "não-ser" entendido, não como um conceito como outros, mas como negativa de todo conceito. O "ser" "se afirma criadoramente, conquistando eternamente seu próprio não-ser. Como tal é o modelo da auto-afirmação de cada ser finito e a fonte de coragem do ser" (TILLICH, 1976, p.27). Por sua vez, "coragem é auto-afirmação 'a-despeito-de', isto é, a despeito daquilo que tende a impedir o eu de se afirmar" (TILLICH, 1976, p.25). E, em meio a este raciocínio, Tillich (1976, p.28) afirma a necessidade da inclusão de uma ontologia da ansiedade numa ontologia da coragem da seguinte forma:

Não obstante, é necessário incluir uma ontologia da ansiedade numa ontologia da coragem, porque são interdependentes. E é possível que, à luz de uma ontologia da coragem, tornem-se visíveis alguns aspectos da ansiedade. Esta é a primeira assertiva sobre a natureza da coragem: ansiedade é o estado no qual um ser tem ciência de seu possível não-ser. O mesmo raciocínio, resumido, seria: ansiedade é a consciência existencial do não-ser. "Existencial" nesta frase significa que não é o conhecimento abstrato de não-ser que produz ansiedade, mas consciência de que não-ser é uma parte do nosso próprio ser. Não é a certeza da transitoriedade universal, nem mesmo a experiência da morte dos outros, porém a impressão de tais acontecimentos na sempre latente consciência de nosso próprio "ter de morrer", produz ansiedade. Ansiedade é finidade, experimentada como nossa própria finidade. Esta é a ansiedade natural do homem como homem, e de certa forma de todos os seres viventes. É ansiedade de não-ser, a certeza de nossa finidade como finidade.

Tillich expõe que o "não-ser" é dependente do "ser" que nega, há uma prioridade ontológica do "ser" sobre o "não-ser", algo que já está logicamente implícito no próprio termo "não-ser". Ou seja, para que haja uma negação é necessária uma afirmação precedente. Além disto, o "não-ser" é dependente das qualidades especiais do "ser" ao qual nega. E, assim, Tillich expõe a possibilidade de se falar das qualidades do "não-ser" e, por consequência, de tipos de ansiedade. Ele distingue três tipos de ansiedade conforme as direções nas quais o "não-ser" ameaça o "ser".

O não-ser ameaça a auto-afirmação "ôntica" do homem, de modo relativo, em termos de destino, de modo absoluto, em termos de morte. Ameaça a auto-afirmação espiritual do homem, de modo relativo em termos de vacuidade, de modo absoluto, em termos de insignificação. Ameaça a 
auto-afirmação moral do homem, de modo relativo em termos de culpa, de modo absoluto, em termos de condenação. A confirmação desta ameaça tripla é a ansiedade, aparecendo de três formas, a do destino e da morte (em resumo, a ansiedade da morte), a do vazio e da perda de significação (em resumo, a ansiedade da vacuidade), a da culpa e condenação (em resumo, a ansiedade da condenação). Em todas as três formas a ansiedade é existencial, no sentido de que pertence à existência como tal, não a um estado anormal da mente como na ansiedade neurótica (e psicótica) (TILLICH, 1976, p.32).

Para os interesses da discussão proposta aqui acerca do fundamentalismo, importa compreender a "ansiedade da vacuidade" que se relaciona com a ameaça à auto-afirmação espiritual humana. Essa auto-afirmação, segundo Tillich, ocorre em cada momento em que o ser humano vive criadoramente nas várias esferas de significação. $\mathrm{O}$ elemento criador, neste contexto, está relacionado a viver espontaneamente, em ação e reação, com o conteúdo da vida cultural. Afirma-se espiritualmente quando se recebe e transforma a realidade de modo criador. Uma vida na qual isto não é experimentado é ameaçada pelo "não-ser" de duas formas: vacuidade e insignificação. O termo insignificação é utilizado para a ameaça absoluta do "não-ser" à auto-afirmação espiritual, e o termo vacuidade para a ameaça relativa a ela. Embora na base da vacuidade esteja a insignificação. Tillich (1976, p.37) explica que:

A ansiedade da vacuidade é despertada pela ameaça do não-ser ao conteúdo especial da vida espiritual. Uma certeza rompe através dos acontecimentos externos ou processos interiores: somos cortados da participação criadora numa esfera de cultura, nos sentimos frustrados a respeito de algo que se tinha afirmado com paixão, somos conduzidos da devoção a um objeto, à devoção por outro e de novo por outro, porque o sentido de cada um deles se desvanece e o eros criador se transformou em indiferença ou aversão. Tudo é tentado e nada satisfaz. O conteúdo da tradição, embora excelente, embora louvado, embora amado antes, perde seu poder de dar conteúdo hoje. E a cultura presente é ainda menos capaz de prover conteúdo. Ansiosamente nos voltamos para longe de todo o conteúdo concreto e procuramos um significado básico, só para descobrir que foi precisamente a perda de um centro espiritual que retirou o significado do conteúdo especial da vida espiritual. Mas um centro espiritual não pode ser produzido intencionalmente, e a tentativa de produzi-lo só produz ansiedade mais espessa. A ansiedade da vacuidade conduz-nos ao abismo da insignificação. 
Esta crise espiritual que se instaura mantém relações com a dúvida oriunda da incapacidade de lidar com o novo e com as mudanças na cultura. Porém não se trata de qualquer dúvida. Tillich explica que o que ameaça à vida espiritual não é a dúvida como um elemento, mas dúvida total. Pois dúvida enquanto questionamento da realidade, em sentido cartesiano, é uma condição da vida espiritual humana. A dúvida total é a que deixou de ser indagação metodológica e se tornou desespero existencial. Em meio a dúvida, apega-se a conteúdos que ainda não estejam minados tais como tradições, convicções autônomas ou preferências emocionais. E na impossibilidade de remover a dúvida, aceita-se o fato com coragem, sem renunciar às convicções pessoais. Tudo isto se constitui em esforço para evitar a situação extrema, sucumbir ao completo desespero da verdade. Mas há ainda outro caminho que pode ser seguido, e este tem forte relação com a atitude fundamentalista. Sobre isto, Tillich (1976, p.38) acrescenta:

O homem tem um outro caminho: a dúvida se baseia na separação do homem do todo da realidade, da sua falta de participação universal, no isolamento de seu eu individual. Ele tenta sair desta situação, renunciar à sua separação e auto-relacionamento. Voa da liberdade de perguntar e responder por si mesmo, para uma situação na qual não podem ser formuladas questões ulteriores e as respostas às questões prévias são impostas a ele autoritariamente. A fim de evitar o risco de perguntar e duvidar, ele renuncia ao risco de perguntar e duvidar. Renuncia a si próprio tentando salvar sua vida espiritual. Ele "foge de sua liberdade" (Fromm) tentando fugir à ansiedade da insignificação. Agora ele não mais está sozinho, nem na sua dúvida existencial, nem no desespero. Ele "participa" e afirma pela participação o conteúdo de sua vida espiritual. A significação está salva, mas o eu é sacrificado. E desde que a submissão da dúvida foi matéria de sacrifício, o sacrifício da liberdade do eu, deixa sua marca na certeza reconquistada: uma auto-agressividade fanática. $\mathrm{O}$ fanatismo é o correlato de auto-rendição espiritual: mostra ansiedade que supostamente estava dominada, atacando com violência desproporcionada aqueles que discordam e que demostram, por sua discordância, elementos que o fanático deve suprimir ele mesmo de sua vida espiritual. Porque deve suprimi-los de dentro dele, tem ele que suprimi-los nos outros. Sua ansiedade força-o a perseguir os que dissentem.

A interpretação teológica do fundamentalismo demonstrou que este apresenta traços idolátricos por elevar o relativo e transitório à condição 
de absoluto, elevar o que é preocupação preliminar à ultimacidade. Por sua vez, também se evidencia demoníaco, agindo como destruidor da racionalidade, pois age potencializando elementos na própria mente que acarretam a sua destruição. Por fim, o fundamentalismo opera como sacrifício da liberdade do eu, auto-rendição espiritual.

\section{Bíblia e Relações de Gênero}

A discussão que foi apresentada até o momento servirá como base para o que se propõe a expor neste ponto. A Bíblia tem sido tomada como "fundamento" para um tipo de fundamentalismo específico, o fundamentalismo bíblico. E conforme a abordagem teológica demonstrou, dentre outras coisas, o fundamentalismo se caracteriza idolatricamente. Isto, no tocante à Bíblia, se manifesta por meio da elevação desta, ou melhor dizendo, de uma forma de a interpretar e dos resultados desta interpretação à uma condição absoluta. $\mathrm{O}$ transitório e histórico-culturalmente condicionado na Bíblia é elevado à ultimacidade. $\mathrm{O}$ que, segundo a perspectiva teológica que foi exposta assume características demoníacas, destruidoras da racionalidade, pois se torna um forte instrumento de poder sobre as mentes. Exatamente por conduzir ao sacrifício do eu, ou sacrifício da liberdade de questionar em nome de supostas certezas.

O biblicismo (outro nome para fundamentalismo bíblico) coloca os leitores da Bíblia fechados numa abordagem hermenêutica cujo propósito é o fortalecimento das mencionadas supostas certezas e a aniquilação de qualquer exercício de dúvida metódica que interrogue acerca da validade destas certezas.

Outra forma desta postura idolátrica se manifestar é por meio do uso do conceito teológico de Palavra de Deus. Sobre isto, não foi casualidade que, em 1895, o grupo de teólogos protestantes conservadores estadunidenses, reunidos na conferência em Niagara Falls, afirmassem (dentre as cinco proposições consideradas inegociáveis) a absoluta inerrância da Bíblia. A principal premissa que oferece suporte para esta proposição é a da "inspiração verbal e plenária da Bíblia", algo que consiste em acreditar que a inspiração se deu através de um ato mecânica de Deus ditar o conteúdo bíblico ou, em termos mais sutis, soprar 
este conteúdo. Acerca disto, em meio a sua exposição sobre êxtase como estado no qual ocorre a revelação, Tillich (2002, p.101-102) escreve:

Com respeito a seu elemento cognitivo, êxtase é frequentemente chamado de "inspiração". Esta palavra é derivada de spirare, "respirar", enfatiza a pura receptividade da razão cognitiva em uma experiência extática. Confusões e distorções foram feitas com o termo "inspiração" a ponto de torná-lo quase tão inútil quanto "êxtase" e "milagre". O vago uso da palavra ao descrever atos não refletidos de conhecimento é em parte responsável por esta situação. Neste uso da palavra, ser inspirado significa estar em um humor criativo, ou ser possuído por uma ideia, ou atingir uma compreensão de uma súbita intuição. $\mathrm{O}$ abuso oposto do termo está ligado a certas formas da doutrina da inspiração dos escritores bíblicos. A inspiração é descrita como um ato mecânico de ditar ou, de forma mais refinada, como um ato de ministrar informação. Nestas ideias de inspiração a razão é invadida por um corpo estranho de conhecimento com o qual não pode estar unida. Este corpo destruiria a estrutura racional da mente se permanecesse dentro dela. Em última análise, uma forma mecânica ou qualquer outra doutrina não-extática de inspiração é demoníaca. Ela destrói a estrutura racional que pretende receber a inspiração.

Bíblia e Palavra de Deus são compreendidas por fundamentalistas como a mesma coisa, do mesmo modo que Deus e a sua Palavra são iguais, nisto jaz o mencionado caráter absoluto e idolátrico do fundamentalismo bíblico. Mas mesmo aceitando que o conteúdo bíblico tenha sido "soprado por Deus" em um processo mecânico de ditado, uma vez que isto aconteça, este conteúdo invade a temporalidade histórica e se relativiza. Aceitando que a revelação tenha ocorrido deste modo, e entendendo que tudo o que estiver condicionado por relações é relativo, a primeira maneira deste conteúdo ditado por Deus se relativizar seria por meio da relação de intersubjetividade, pois um sujeito, Deus, estaria comunicando algo a outros sujeitos (os escritores bíblicos). Depois é preciso considerar que os sujeitos receptores do conteúdo ditado o recebem na temporalidade e espacialidade, estão em algum lugar e em determinada época, isto torna o conteúdo condicionado pelas relações espaço-temporais. E assim, seria possível continuar considerando outras relações possíveis que só reforçam o argumento de que mesmo que a Bíblia tivesse sido enviada completa por Deus, ao entrar em contato com o tempo e espaço, seria relativizada. 
Este argumento está sendo utilizado para que se compreenda que o modo como fundamentalistas bíblicos interpretam a narrativa bíblica, sem considerar os condicionamentos histórico-culturais, dentre outros, faz com que absolutizem e tratem como Palavra de Deus aquilo que é claramente humano. Uma vez que isto seja compreendido, pode-se dispor tanto da perspectiva teológica quanto da sociológica utilizadas até o momento como recursos hermenêuticos para a leitura bíblica.

No tocante a atribuir caráter absoluto a elementos que estão culturalmente condicionados, os fundamentalistas fazem isto por estarem atrelados a um círculo hermenêutico que faz com que reforcem questões de seus próprios contextos culturais, quando estes coincidem com o do texto bíblico. Este é um ponto a ser destacado a respeito das questões de gênero na Bíblia e outras situações análogas (como sexismo, racismo e homofobismo) que preservam uma relação estrutural com a cultura contemporânea e que são reforçadas a partir da leitura do texto bíblico.

Observou-se (quando Tillich (1976) discorreu sobre a situação na qual a auto-afirmação espiritual é atacada) que os sujeitos envolvidos neste processo podem experimentar uma "ansiedade de vacuidade" por não conseguirem viver criadoramente, participando da transformação da realidade que esteja em curso. Os fundamentalistas não conseguem lidar criadoramente com a desnaturalização ou a relativização de elementos na cultura contemporânea provocada pela experiência de pluralismo da Modernidade. Estes reagem a situação absolutizando tais elementos e a Bíblia se torna um instrumento útil para isto. Principalmente quando encontram na situação histórico-cultural na qual a Bíblia foi escrita valores culturais semelhantes aos que desejam absolutizar na situação contemporânea.

O exposto, quando aplicado ao processo interpretativo (seja do texto bíblico ou da realidade), encontra respaldo teórico na abordagem ontológica à hermenêutica feita por Heidegger (2013). O ser que interpreta é um "ser-aí" ou "ser-no-mundo", condicionado, o qual se projeta no objeto de sua interpretação. E ao fazer isto, o "ser-aí" condiciona a sua interpretação. Para Heidegger (2013, p.21), "na hermenêutica configura-se ao ser-aí como uma possibilidade de vir a compreender-se e de ser essa compreensão". 
As culturas em meio as quais o texto bíblico foi escrito estavam marcadas pelo sexismo do mesmo modo que as culturas contemporâneas no Ocidente cristão. $\mathrm{O}$ que os fundamentalistas tem realizado no tocante a isto é fortalecer a identificação deste sexismo como a Palavra de Deus. Pondo, em outras palavras, entendem que o sexismo contemporâneo deve ser conservado e defendido contra os que o ameaçam porque o compreendem como um dado da revelação divina, ou seja, como Palavra de Deus.

Todavia, a situação pluralista na qual as sociedades contemporâneas se encontram tem permitido perceber o óbvio, mas que estava imperceptível devido à sua naturalização, as produções humanas. Não são algo estabelecido por deuses nem tão pouco fruto de um determinismo biológico, uma natureza. Daniel Borrillo (2016, p.23) atrai a atenção para o aspecto ideológico do sexismo:

A ideologia que preconiza a superioridade da raça branca é designada sob o termo "racismo"; a que promove a superioridade de um gênero em relação ao outro se chama "sexismo". O antissemitismo designa a opinião que justifica a inferiorização dos judeus, enquanto a xenofobia refere-se à antipatia diante dos estrangeiros. Portanto, em função do sexo, da cor da pele, da filiação religiosa ou de origem étnica é que se instaura, tradicionalmente, um dispositivo intelectual e político de discriminação. O sistema a partir do qual uma sociedade organiza um tratamento segregacionista segundo a orientação sexual pode ser designado sob o termo geral de "heterossexismo".

O conhecimento da existência da diversidade cultural da humanidade tem demonstrado que as culturas definem os papéis sociais de homens e mulheres de conformidade com processos históricos e formas de representar a realidade característicos de cada cultura. Não restando dúvidas sobre as influências históricas, culturais e ideológicas na definição das relações de gênero. Sexismo é o que promove a crença de que certos papéis não podem ser desempenhados por mulheres, isto tem sido sustentado ao longo da história tanto por discursos religiosos quanto por discursos científicos. Os papéis atribuídos a homens e mulheres foram definidos a partir da naturalização das diferenças entre os dois sexos. Assim, a ordem denominada "natural" dos sexos determina uma ordem social na qual o feminino deve ser complementar do masculino pelo viés 
de sua subordinação psicológica e cultural. Em meio a esta conjuntura Borrillo (2016, p.13) propõe a seguinte definição para sexismo:

O sexismo define-se, desde então, como a ideologia organizadora das relações entre os sexos, no âmago da qual o masculino caracteriza-se por sua vinculação ao universo exterior político, enquanto o feminino reenvia à intimidade e a tudo o que se refere à vida doméstica. A dominação masculina identifica-se com essa forma específica de violência simbólica que se exerce, de maneira sutil e invisível, precisamente porque ela é apresentada pelo dominador e aceita pelo dominado como natural, inevitável e necessária. O sexismo caracteriza-se por uma constante objetificação da mulher.

Borrillo (2016) identificou que o sexismo, enquanto ordem social, implica tanto a subordinação do feminino ao masculino quanto a hierarquização das sexualidades, fundamento da homofobia; por conseguinte, a evocação constante da superioridade biológica e moral dos comportamentos heterossexuais faz parte de uma estratégia política de construção da "normalidade" sexual. A heterossexualidade aparece, assim, como o padrão para avaliar todas as outras sexualidades. Borrillo (2016, p.31) acrescenta:

Essa qualidade normativa - e o ideal que ela encarna - é constitutiva de uma forma específica de dominação, chamada heterossexismo, que se define como a crença na existência de uma hierarquia de sexualidades, em que a heterossexualidade ocupa a posição superior. Todas as outras formas de sexualidade são consideradas, na melhor das hipóteses, incompletas, acidentais e perversas; e, na pior, patológicas, criminosas, imorais e destruidoras da civilização.

Sexismo e heterossexismo estão ideologicamente relacionados por condicionamentos culturais semelhantes. E o que foi mencionado sobre os fundamentalistas estarem atrelados a um círculo hermenêutico que faz com que reforcem questões de seus próprios contextos culturais, quando estes coincidem com o do texto bíblico, também se aplica ao homofobismo estrutural das sociedades contemporâneas e o reforço deste homofobismo através da utilização de meia dúzia de versículos distribuídos entre o Novo e o Antigo Testamentos. 


\section{Considerações finais}

A experiência pluralista que emerge com a Modernidade permite a percepção da relatividade do que outrora foi aceito conforme dado. O mundo social é como é, mas poderia ser diferente. Desperta-se para a contingência que permeia o mundo social.

É claro que com isto "estruturas de plausibilidade" ruíram e com elas se foram muitas das certezas. Para se lidar com esta situação, duas posturas básicas foram assumidas: o fundamentalismo e o relativismo. Acerca do fundamentalismo, muito já foi exposto aqui, todavia sobre o relativismo se pode dizer que, na direção oposta do fundamentalismo, passa-se a advogar a impossibilidade de certezas, e a inexistência de absolutos. Porém, quando se faz isto, acaba-se por afirmar o que se pretende negar, pois pelo menos uma afirmação absoluta precisa haver, a de que não há absolutos.

Mas as coisas não necessitam ser assim. De fato, a humanidade se move em meio a transitoriedade e a contingência, por diversas vezes, caindo na armadilha de absolutizar o transitório e o contingente. Este empreendimento humano revela o esforço existencial para lidar com a "ansiedade de vacuidade e insignificação". O estabelecimento de provas ou de certezas acerca do absoluto, dentre estas, até mesmo a busca por provas acerca da existência de Deus, constituem-se, na verdade, perguntas pela verdade, por um bem ou mal supremos, perguntas por absolutos. Assim, as perguntas, ao invés de destruírem a "auto-afirmação espiritual" como pressupõem os fundamentalistas, são elas que a renovam, que a impulsionam, que não permitem que a espiritualidade se torne estagnada ou que se torne idolátrica e demoníaca.

\section{Referências}

BERGER, Peter L. O Dossel sagrado: elementos para uma teoria sociológica da religião. São Paulo: Paulus, 1985.

. Rumor de anjos: a sociedade moderna e a redescoberta do sobrenatural. Petropólis: Vozes, 2018.

. O imperativo herético: possibilidades contemporâneas da afirmação religiosa. Petropólis: Vozes, 2017. 
Os múltiplos altares da modernidade: rumo a um paradigma da religião numa época pluralista. Petropólis: Vozes, 2017.

BORRILLO, Daniel. Homofobia: história e crítica de um preconceito. Belo Horizonte: Autêntica, 2016.

HEIDEGGER, Martin. Ontologia: hermenêutica da facticidade. Petrópolis: Vozes, 2013.

MANNHEIM, Karl. Ideologia e utopia: introdução à sociologia do conhecimento. São Paulo: Editora Globo, 1952.

TILLICH, Paul. Teologia Sistemática. São Leopoldo: Sinodal, 2002.

. A coragem de ser. Rio de Janeiro: Paz e Terra, 1976.

Submetido em: 3-4-2021

Aceito em: 3-9-2021 